\title{
Association of Obesity Indices with Acute Myocardial Infarction
}

\author{
Authors \\ Dr Suresh Raghavan ${ }^{1}$, Dr Arathi $\mathbf{N}^{2 *}$ \\ ${ }^{1}$ Professor, Department of Medicine, Government TD Medical College, Alappuzha \\ ${ }^{2}$ Assistant Professor, Department of Medicine, Government TD Medical College, Alappuzha \\ *Corresponding Author \\ Dr Arathi N \\ Assistant Professor, Department of Medicine, Government TD Medical College, \\ Vandanam PO, Alappuzha: 688005 \\ Mobile: 9446724558, Email: arathi.n.iyer@gmail.com
}

\section{Introduction}

Obesity is a known risk factor for the development of myocardial infarction. The indices that are popularly used to express obesity areBody mass index (BMI), waist-hip ratio, and waist circumference. The latter two are indicators of body fat distribution and has found to predict cardiometabolic risk independent of the BMI in both men and women. ${ }^{[1-7]}$

This study aims to compare the association of BMI, waist- hip ratio and waist circumference with myocardial infarction.

\section{Aims and Objectives}

1. To find out difference in BMI and body fat distribution in patients with myocardial infarction as compared to those without myocardial infarction.

2. To compare the strength of association of BMI, waist-hip ratio and waist circumference with the occurance of myocardial infarction.

\section{Materials and Methods}

\section{Study Design}

The study was designed to be a Case- control study and was conducted in a tertiary care centre in South Kerala. The minimum sample size was calculated from a previous study.[8] and was found to be 58.5. A total of 120 people were studied, of which 60 were cases and 60 were controls.

\section{Cases}

Patients admitted to the Department of Medicine with a diagnosis of acute Myocardial Infarction according to the WHO criteria, above the age group of 18 years.

\section{Exclusion Criteria}

1. Patients who were not it for ambulation.

2. Those who do not give consent.

\section{Controls}

Bystanders of patients admitted to the institution who were comparable with the cases on the basis of age and gender.

\section{Exclusion criteria}

1. People with known coronary artery disease 
2. Those who were not willing to give consent.

Data collection was with the help of questionnaire and was done only when the patients were fit for ambulation. Weight was measured using Tanita UM-081 BIA device, that gives weight measurement caliberated to $0.1 \mathrm{~kg}$. Height was measured on a standard stadiometer. Waist Circumference was measured at the midpoint between the lowest ppoint of the costal cartilage and the upper part of the iliac crest in the mid axillary line conforming to the WHO recommendations ${ }^{[9]}$. Hip circumference was measured at the level of the largest circumference of the buttocks, confirming to the WHO recommendations ${ }^{[9]}$. BMI was measured as (weight in kilograms)/ (height in meters) ${ }^{2}$. Waist - hip ratio is the waist circumference in centimeters divided by the hip circumference in centimeters. For hypertension, diabetes and dyslipidemia, self reporting was taken similar to the INTERHEART study ${ }^{[10]}$.
Current smokers are defined by a regular habit of smoking at least 1 cigarette per day for at least 3 months within the past 6 months. Reformed smokers were not considered.

BMI cut offs were $\geq 23$ in asian population.

Waist circumference is considered abnormal if > $80 \mathrm{cms}$ for females and $>90 \mathrm{cms}$ for males.

Waist - hip ratio: The cut offs were 0.90 in males and 0.85 in females ${ }^{[9]}$.

Data analysis was done with SPSS software version 17.0.

\section{Observations and Results}

\section{Age distribution of Cases and Controls:}

Since the anthropometric parameters vary with age, it is important to ensure that both the cases and controls are comparable with respect to age. The analysis given below shows that the cases and controls do not have any significant difference, with respect to the age. Chi square 5.099, $\mathrm{df}=3$, p value $=0.165$

Table1: Age distribution of cases and controls

\begin{tabular}{|l|c|c|c|c|c|c|}
\hline Age Group & \multicolumn{2}{|c|}{ Cases } & \multicolumn{2}{c|}{ Controls } & \multicolumn{2}{c|}{ Total } \\
\hline & $\mathrm{N}$ & $\%$ & $\mathrm{~N}$ & $\%$ & $\mathrm{~N}$ & $\%$ \\
\hline$<50$ years & 10 & $16.7 \%$ & 12 & $20 \%$ & 22 & $18.3 \%$ \\
\hline 50-59 years & 16 & $26.7 \%$ & 20 & $33.3 \%$ & 36 & $30.0 \%$ \\
\hline 60-69 years & 20 & $33.3 \%$ & 23 & $38.3 \%$ & 43 & $35.8 \%$ \\
\hline$\geq 70$ years & 14 & $23.3 \%$ & 5 & $8.3 \%$ & 19 & $15.8 \%$ \\
\hline Total & 60 & $100 \%$ & 60 & $100 \%$ & 120 & $100 \%$ \\
\hline
\end{tabular}

Since anthropometric parameters vary with gender as well, comparability should be ensured with respect to the number of subjects from each gender.

Table 2: Gender distribution of cases and controls

\begin{tabular}{|l|c|c|c|c|c|c|}
\hline GENDER & \multicolumn{2}{|c|}{ Cases } & \multicolumn{2}{c|}{ Controls } & \multicolumn{2}{c|}{ Total } \\
\hline & $\mathrm{N}$ & $\%$ & $\mathrm{~N}$ & $\%$ & $\mathrm{~N}$ & $\%$ \\
\hline Male & 43 & $71.7 \%$ & 43 & $71.7 \%$ & 86 & $71.7 \%$ \\
\hline Female & 17 & $28.3 \%$ & 17 & $28.3 \%$ & 34 & $28.3 \%$ \\
\hline TOTAL & 60 & $100 \%$ & 60 & $100 \%$ & 120 & $100 \%$ \\
\hline
\end{tabular}

(Chi square $0.000, \mathrm{df}=1$. $\mathrm{p}$ value 1.000 )

The table shows that the cases and the controls were comparable. 


\section{JMSCR Vol||07||Issue ||04||Page 506-510||April}

Figure 1: Waist Circumference among cases and controls

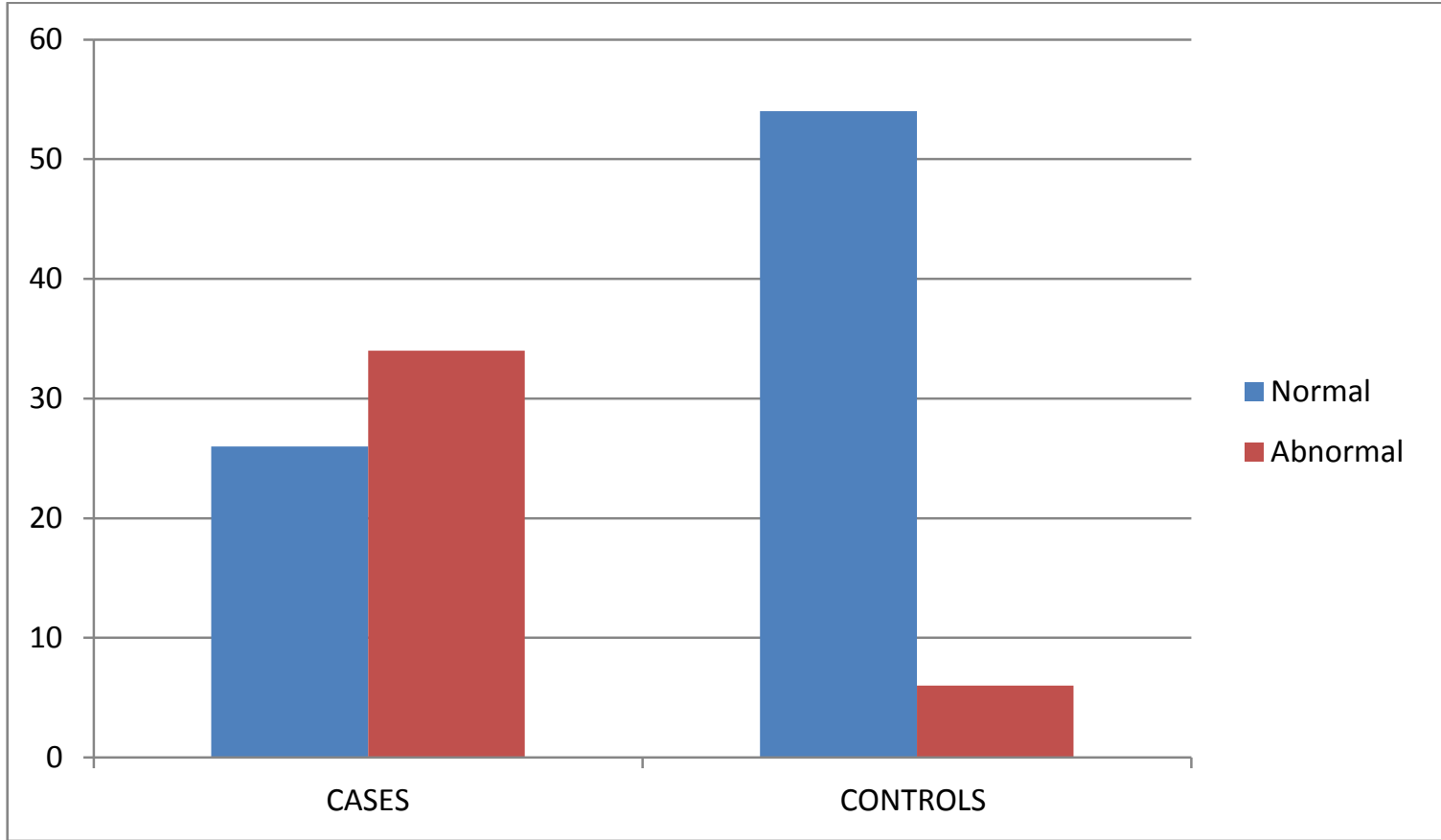

Abnormal waist circumference was found to be significantly higher in cases when compared to controls. (Chi square 29.4, $\mathrm{df}=1$, p value $<0.001$ ) and was found to be strongly associated with myocardial infarction. (Odds ratio $11.769,95 \%$ CI 4.391-31.546).

Figure 2: Waist- hip ratio among cases and controls

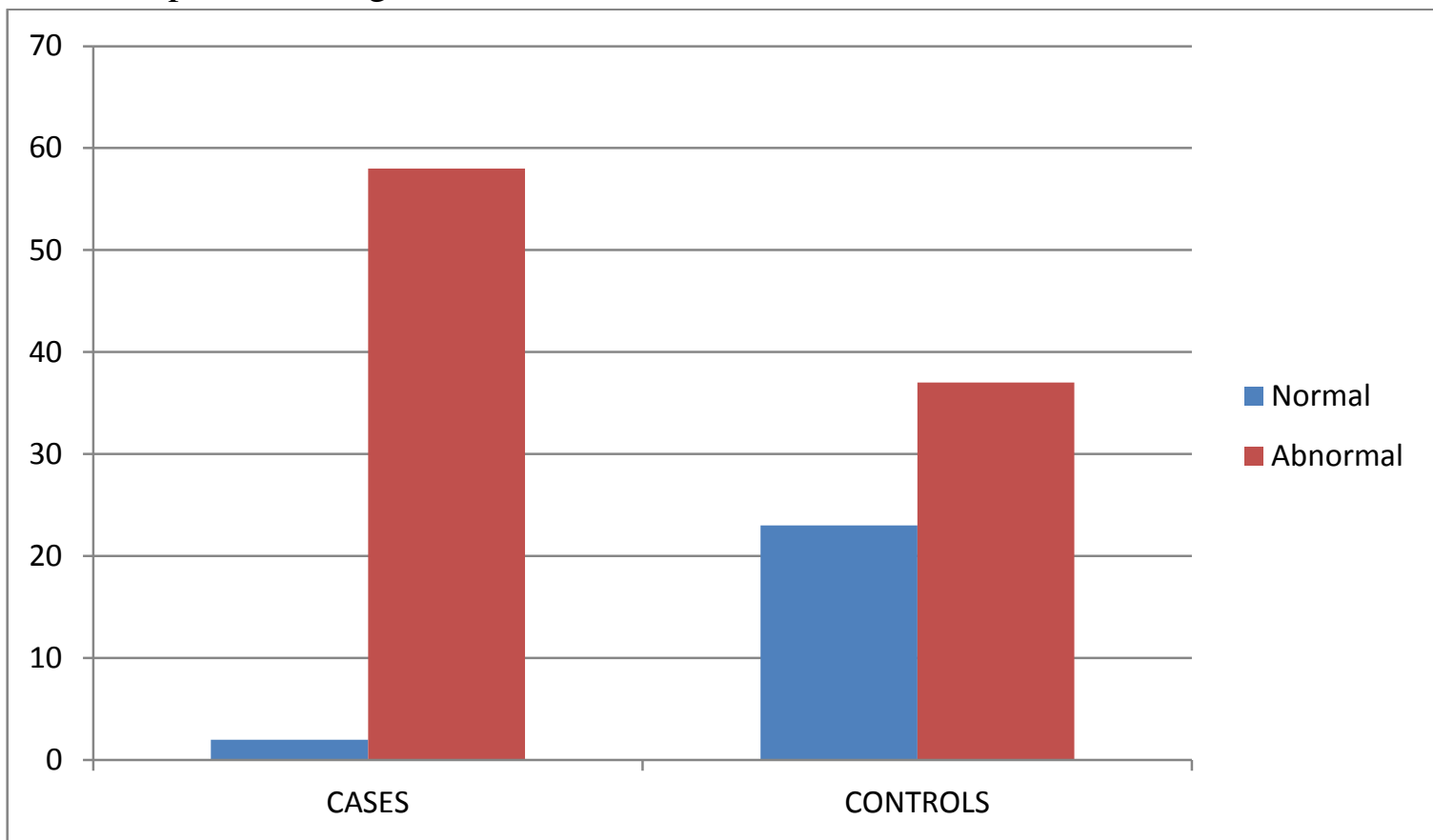

Abnormal waist hip ratio was also found to be significantly higher in cases when compared to controls. (chi square 22.282, $\mathrm{df}=1, \mathrm{p}$ value $<0.001)$. There was a strong association between abnormal waist hip ratio and myocardial infarction. (Odds ratio 18. 027, $\mathrm{CI}=4.102$ 81.002). 
Figure 3: BMI among cases and controls

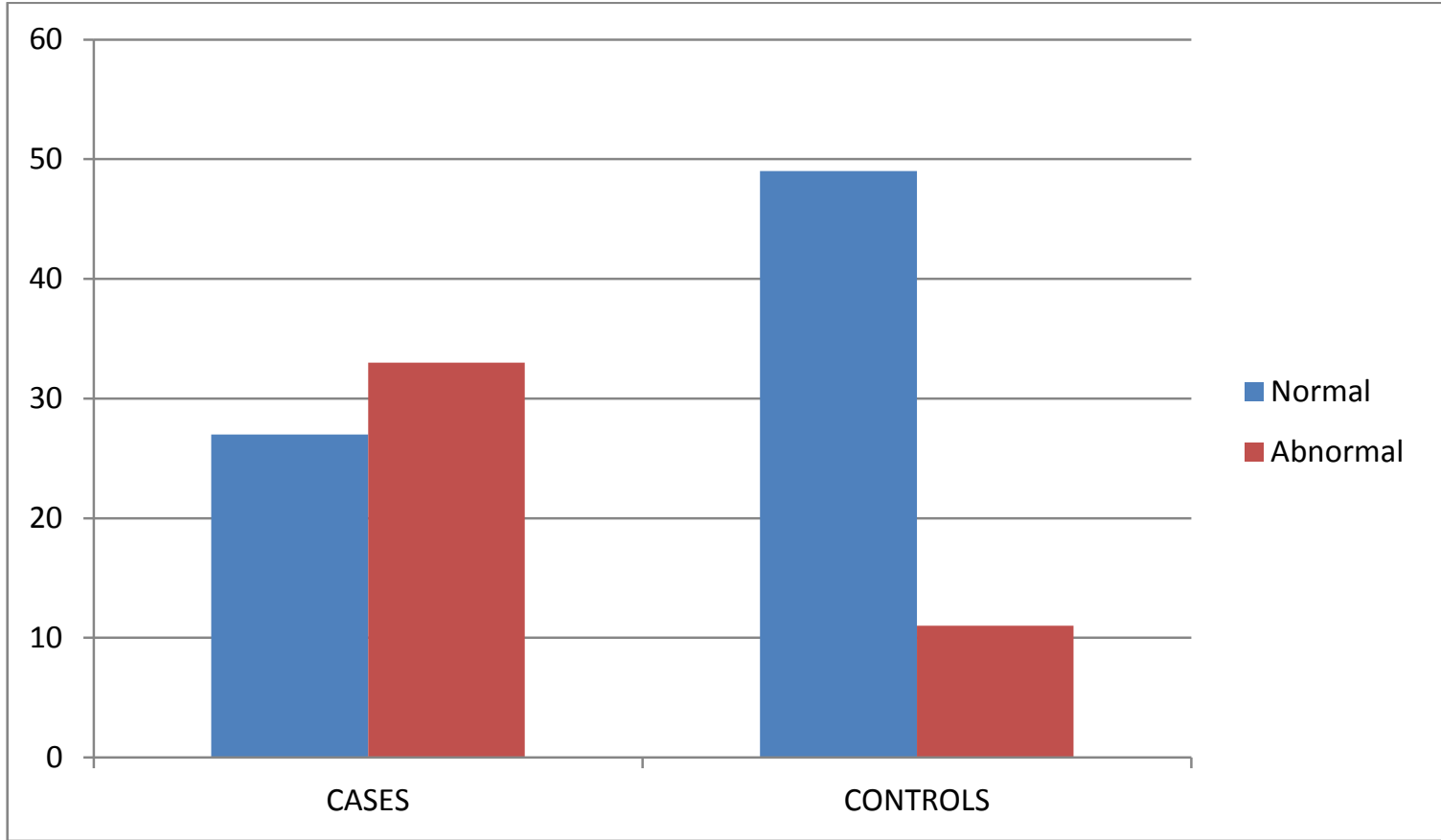

Abnormal BMI was found to be significantly higher in cases when compared to controls (Chi found to be strongly associated with myocardial infarction. square $17.368, \mathrm{df}=1 ; \mathrm{p}$ value $<0.001$ ) and was

Table 3: Multivariate Analysis

\begin{tabular}{|l|l|l|l|l|l|l|l|l|}
\hline & B & SE & Wald & df & Sig & Exp(B) & \multicolumn{2}{|l|}{ 95\% CI for Exp(B) } \\
\cline { 5 - 9 } & & & & & & & Lower & Upper \\
\hline Abnormal waist circumference & .961 & .691 & 1.757 & 1 & & .185 & .645 & 9.685 \\
\hline Abnormal waist- hip ratio & 1.86 & .843 & 4.872 & 1 & & .027 & 1.232 & 33.556 \\
\hline Abnormal BMI & -.060 & .648 & .009 & 1 & & .926 & .265 & 3.35 \\
\hline Constant & -1.81 & .471 & 14.853 & 1 & & .000 & & \\
\hline
\end{tabular}

Multivariate analysis of the anthropometric parameters showed waist hip ratio to be significantly associated with myocardial infarction. $\mathrm{P}$ value $<0.05$.

\section{Discussion}

Abnormal body mass index, waist circumference and waist hip ratio were associated with myocardial infarction. This has been conclusively proven by studies from India and abroad ${ }^{[6,10,11]}$. Several previous studies including the large multi centre land mark INTERHEART study has found that waist hip ratio is more significant than the waist circumference in cardiovascular risk assessment, similar to the results in our study ${ }^{[5,12]}$. Multivariate analysis of anthropometric parameters showed that waist hip ratio to be significantly associated with a risk of myocardial infarction.
Our study therefore concludes that waist hip ratio measurement may obviate the need for any other measures of corpulence or obesity.

\section{References}

1. Lapidus 1 et al. Distribution of adipose tissue and risk of cardiovascular disease and death: A 12 year follow up of participants in the population study of women in Gothenburg, Sweden. British Medical Journal. 1984;289: 1257-61.

2. SEidell JC, Cigolini M, Charzweska J, Ellisinger $\mathrm{BM}$ and di Biase. Fat distribution in European women: A comparison of anthropometric measurements in relation to cardiovascular risk factors. International Journal of epidemiology. 1990; 19: 303-308. 
3. Kannel WB et al. Regional Obesity and risk of cardiovascular disease; The Framingham study. Journal of clinical epidemiology. 1991;44: 183-190.

4. Hauner $\mathrm{H}$ et al. Body fat distribution in men with angiographically confirmed coronary artery disease. Atherosclerosis. 1990: 85: 203-10.

5. Wellborn TA, Dhaliwal SS, Bennett SA. Waist Hip ratio is the dominant risk factor predicting cardiovascular risk in Australia. The Medical Journal OfAustralia. 179: 580-85.

6. Leitzmann MF et al. waist Circumference as compared with body mass index in predicting mortality from specific causes. Plos one;2011: 6 e 18582.

7. Klein $\mathrm{S}$ et al. Waist Circumference and cardiometabolic risk: A consensus statement from shaping Americas health: Association for weight management and obesity prevention and the American Diabetes Association. Obesity( Silver Spring Md). 2007;15:1061-7.

8. Amani R, Noorizadeh M, Rahm,anian S, Afzali $\mathrm{N}$ and Haghighizadeh $\mathrm{MH}$. Nutritional related cardiovascular risk in patients with coronary artery disease in Iran: A case control study. Nutrition Journal. 2010;9:70.

9. WHO waist circumference and waist hip ratio: Report of a WHO Expert Consultation. (Geneva, 2008).

10. Yusuf $\mathrm{S}$ et al. Effect of potentially modifiable risk factors associated with myocardial infarction in 52 countries, the INTERHEART study. A case control study. Lancet. 2004;364:937-952.

11. Pais $\mathrm{P}$ et al. Risk factors for acute myocardial infarction in Indians: A case control study. Lancet.1996;348: 358-63.
12. De Koning L, Merchant AT, Pogue J and Anand SS. Waist Circumference and waist hip ratio as predictors of cardiovascular events: meta regression analysis of prospective studies. European Heart Journal. 2007;28: 850-856. 